\title{
Increasing incidence of coeliac disease in Sweden
}

\author{
H Ascher, I Krantz, B Kristiansson
}

\begin{abstract}
Changes in the incidence of coelic disease was studied among children born in Göteborg, Sweden, between 1970 and 1988. A total of 188 patients with coeliac disease were found. Of these, $83 \%$ were less than 2 years old at the time of their first duodenal biopsy and $74 \%$ of them have so far been verified according to the criteria of the European Society for Gastroenterology and Nutrition (ESPGAN). The cumulative incidence at 2 years of age/1000 liveborn infants increased significantly from 0.31 in the first birth cohort to 2.93 in the last. This increase could only partly be explained by improvements in detection. Weight for age at diagnosis was generally considerably below the reference value, but was slightly less affected towards the end of the period. The increase in incidence of coeliac disease is the first reported since the middle 1970s and makes the disease one of the most common chronic diseases among Swedish children.
\end{abstract}

Since the middle of the 1970 s, coeliac disease in childhood has been reported to be decreasing in England, ${ }^{1-4}$ Scotland, ${ }^{5}$ and Ireland. ${ }^{6}$ The incidence and clinical picture have remained unchanged in Italy. ${ }^{7}$ In Finland a decrease in the number of cases diagnosed, together with a changing clinical pattern of a late start and mild course, led to the conclusion that the real incidence was probably unchanged. ${ }^{8}$

In this study we report the changes in the incidence of childhood coeliac disease during the last 20 years in Göteborg, the second largest city in Sweden, which had 435842 inhabitants in 1979 (the middle of the study period) and a computer based population register. The city, like Sweden in general, has a comprehensive child health service with child health centres attended by $98 \%$ of all infants and young children. $^{9}$

\section{Patients and methods}

All children with coeliac disease who were attending the Department of Paediatrics, University of Gothenburg, at East Hospital, Göteborg, Sweden were investigated retrospectively. The hospital has the only paediatric department in the city and is the only place where small intestinal biopsy is done. All children with coeliac disease born between 1970 and 1988 were identified. Those born outside the city were excluded. The starting year 1970 was chosen because small intestinal biopsy was not a routine investigation before that.

To confirm the diagnosis of coeliac disease, at least three small intestinal biopsy specimens were taken when the child was eating different diets according to the criteria of the European Society for Gastroenterology and Nutrition (ESPGAN). ${ }^{1011}$ Four children, born in 1971, 1972,1973 , and 1980 (the first of them being more than 2 years old at the time of the first small intestinal biopsy) were regarded as verified according to the ESPGAN criteria, although they had not had a small intestinal biopsy specimen taken while on a gluten free diet. Children with typical symptoms, an initial flat mucosa, and a distinct clinical response to a gluten free diet but who had not yet fulfilled all the criteria, were also included in the study. Children with suspected coeliac disease but with a less convincing clinical course or histopathological changes were excluded.

The small intestine was biopsied under fluoroscopic control with a Watson capsule, paediatric size. The histopathological picture was classified according to a five point scale by a pathologist who specialised in gastroenterological pathology. ${ }^{12}$

The age at diagnosis, defined as the time of the first small intestinal biopsy, was determined. Cases diagnosed before the age of 2 years were identified. The number in each birth cohort was divided by the number of liveborn infants in Göteborg of that year, giving the cumulative incidence at the age of 2 years for each birth cohort. For each patient who was less than 2 years old at the time of diagnosis, the weight for age at the first biopsy expressed as SD scores of the reference population was calculated. ${ }^{13}$ Weight for age, onset of symptoms, and time from onset to diagnosis, were consecutively recorded and extracted.

To analyse the significance of differences between proportions we used the $\chi^{2}$ test. Linear regression was used to assess time trends.

\section{Results}

Altogether 188 children with coeliac disease born between 1970 and 1988 were investigated and treated at the department of paediatrics up to 1 June 1990 . Of the total, $134(71 \%)$ have been verified according to the ESPGAN criteria. ${ }^{1011}$

Between 1971 and 1975, a mean of five new cases of coeliac disease were diagnosed each year. This number increased to 18 for the years 19859 (fig 1). At the time of diagnosis 156 children $(83 \%)$ were less than 2 years old. Of these, 116 (74\%) have been verified according to the ESPGAN criteria so far (table). Only 10 of the 188 children $(5 \%)$ were more than 7 years old. Between 1970 and 1977 only children less than 2 years old were diagnosed as having coeliac dis-
Correspondence to: Dr Ascher.

Accepted 15 November 1990 


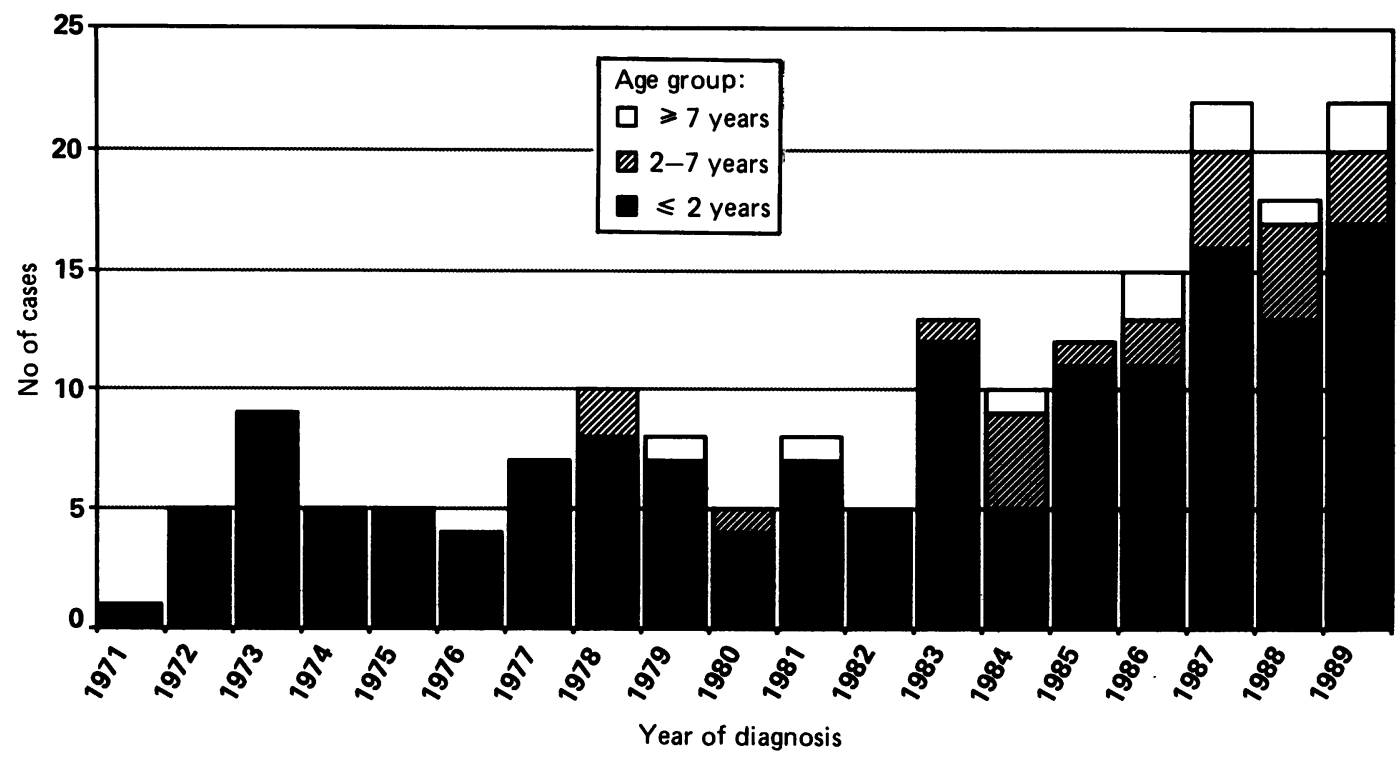

Figure 1 New cases of coelic disease by age group and year of first small intestinal biopsy.

Number of patients and cumulative incidence of coeliac disease at 2 years of age/1000 liveborn infants

\begin{tabular}{|c|c|c|c|c|c|}
\hline Year of birth & Total No & $\begin{array}{l}\text { Verified according } \\
\text { to ESPGAN } \\
\text { criteria }\end{array}$ & $\begin{array}{l}\text { Two small } \\
\text { intestinal biopsy } \\
\text { specimens taken }\end{array}$ & $\begin{array}{l}\text { One small } \\
\text { intestinal biopsy } \\
\text { specimen taken }\end{array}$ & $\begin{array}{l}\text { Cumulative } \\
\text { incidence }\end{array}$ \\
\hline $\begin{array}{l}1970 \\
1971 \\
1972 \\
1973 \\
1974 \\
1975 \\
1976 \\
1977 \\
1978 \\
1979 \\
1980 \\
1981 \\
1982 \\
1983 \\
1984 \\
1985 \\
1986 \\
1988\end{array}$ & $\begin{array}{r}2 \\
4 \\
9 \\
6 \\
4 \\
3 \\
8 \\
10 \\
5 \\
6 \\
5 \\
6 \\
8 \\
10 \\
8 \\
17 \\
14 \\
13 \\
18\end{array}$ & $\begin{array}{r}2 \\
3 \\
8 \\
5 \\
4 \\
3 \\
7 \\
10 \\
5 \\
4 \\
3 \\
4 \\
8 \\
10 \\
7 \\
15 \\
9 \\
7 \\
2\end{array}$ & $\begin{array}{l}0 \\
0 \\
0 \\
0 \\
0 \\
0 \\
0 \\
0 \\
0 \\
2 \\
1 \\
0 \\
0 \\
0 \\
0 \\
2 \\
2 \\
4 \\
6\end{array}$ & $\begin{array}{c}0 \\
1 \\
1 \\
1 \\
0 \\
0 \\
1 \\
0 \\
0 \\
0 \\
1 \\
2 \\
0 \\
0 \\
1 \\
0 \\
3 \\
2 \\
10\end{array}$ & $\begin{array}{l}0.31 \\
0.60 \\
1.44 \\
1.01 \\
0.67 \\
0.54 \\
1.53 \\
1.96 \\
1.02 \\
1.18 \\
0.99 \\
1.22 \\
1.57 \\
2.06 \\
1.54 \\
3.19 \\
2.58 \\
2.21 \\
2.93\end{array}$ \\
\hline Total & 156 & 116 & 17 & 23 & \\
\hline
\end{tabular}

ease. Not until 1979 was the diagnosis applied to children over 7 years of age (fig 1). Of the 188 patients, $131(70 \%)$ were girls, which is significantly more than the expected number $(p<0.001)$. The preponderance of girls did not change during the period of investigation.

The cumulative incidence at 2 years of age for each birth cohort increased from $0.31 / 1000$ liveborn infants in 1970 to $2 \cdot 93 / 1000$ in 1988 (table, fig 2). The last figure is a minimum, because

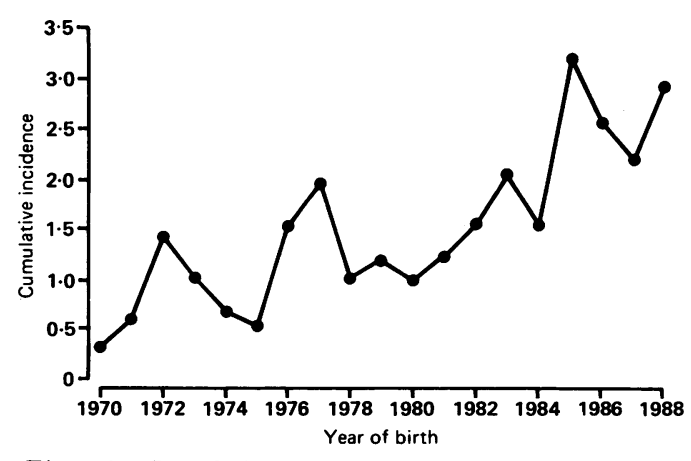

Figure 2 Cumulative incidence of coelic disease at 2 years of age/ 1000 liveborn infants by birth cohort. not all children in the last cohort had reached the age of 2 years by the end of the study period. A linear regression was fitted to the data. The regression (b), that is the average yearly increase, was $0 \cdot 12 / 1000 /$ year $(p<0.0001$, SE 0.02$)$.

In the group in which coeliac disease had been diagnosed before the age of 2 years, the age at the onset of symptoms increased from a mean

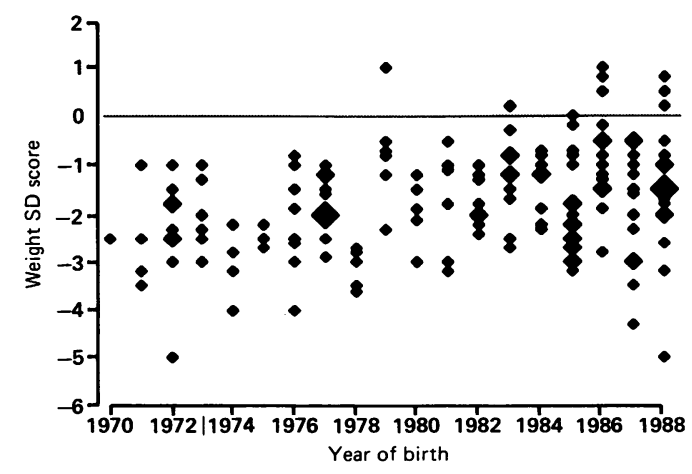

Figure 3 Weight attained at the time of first small intestinal biopsy in children with coeliac disease $<2$ years of age related to their birth year. 


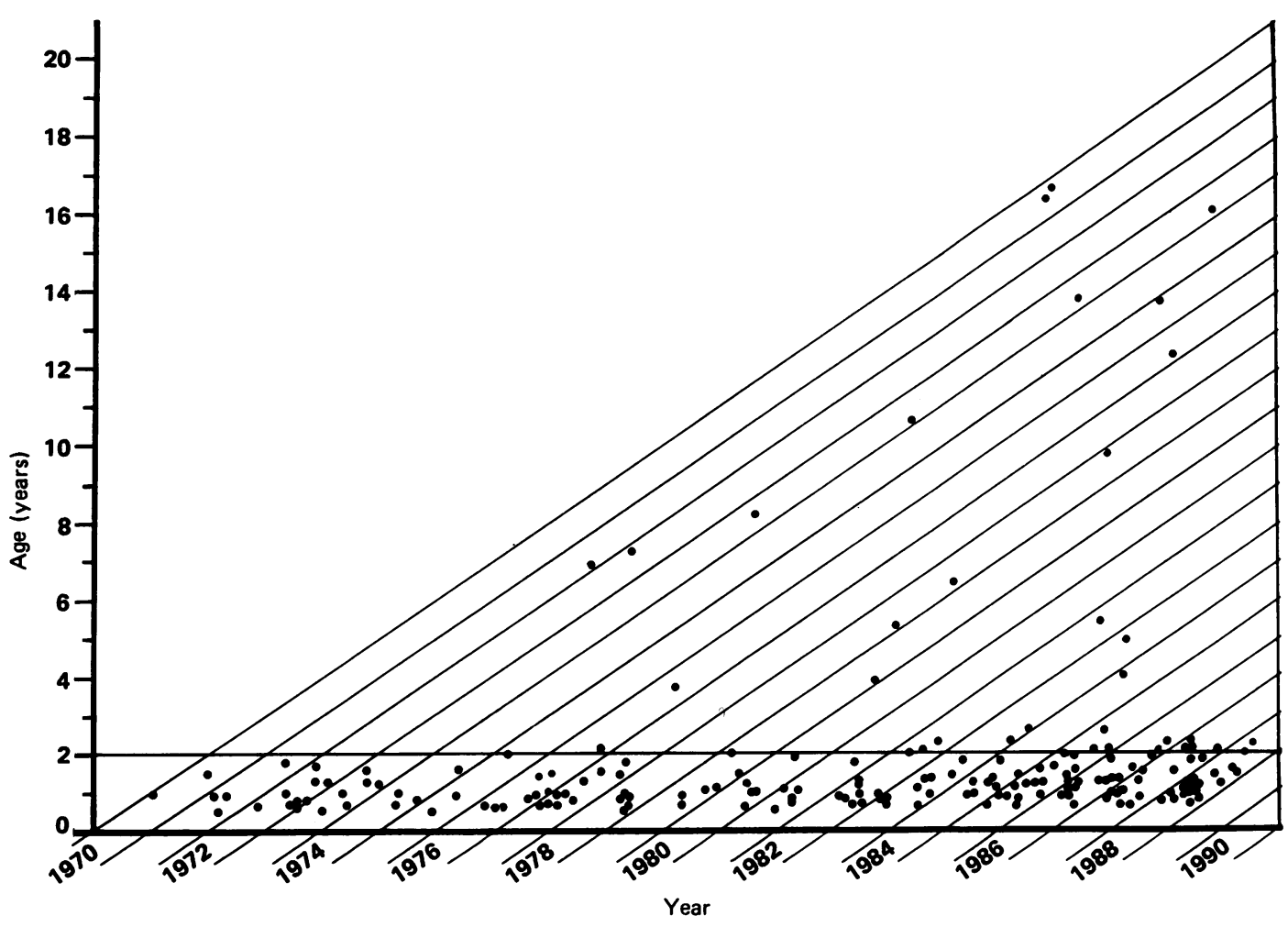

Figure 4 Age at diagnosis of coelic disease related to birth cohort (fields within oblique lines) and year of diagnosis. Solid circles indicate patients with coelic disease.

of 6.7 months in the first half of the observation period to $8 \cdot 2$ months in the second half $(p<0.0004, b=0 \cdot 17$, SE 0.05).

The age at diagnosis increased from a mean of 12.4 months in the first half of the observation period to 13.4 in the last five months $(p<0.05$, $b=0 \cdot 14$, SE $0 \cdot 07$ ). The mean time between onset and diagnosis did not change significantly, being $5 \cdot 3$ months for the whole period.

Weight at the time of diagnosis among children with coeliac disease diagnosed before the age of 2 years was generally far below the reference mean (fig 3 ). When a linear regression was fitted to the data, a slight but significant increase was found $(p=0.0001, b=0.06, S E$ 0.02 ), but variations in weight increased during the second half of the 1980 s.

\section{Discussion}

We have retrospectively studied the incidence of coeliac disease in birth cohorts born in Göteborg from 1970 to 1988 , and found a threefold increase over the period. Of the 188 children studied, $83 \%$ were less than 2 years old at the time of the first small intestinal biopsy.

The first Swedish studies of children using the same diagnostic criteria as we used showed an incidence of between 1.02 and $1 \cdot 16 / 1000$ liveborn infants. ${ }^{14}$ 15 Later reports showed that the incidence was unchanged. ${ }^{16-18}$ In another Swedish study 1866 healthy blood donors were tested with antigliadin antibodies and those with increased titres were offered a small intestinal biopsy. ${ }^{19}$ An incidence of coeliac disease of $3 \cdot 7 / 1000$ was found.

In other parts of Europe, coeliac disease was reported to be increasing until the middle of the 1970s. ${ }^{14572021}$ This was probably the result of a more active diagnostic approach, particularly the increased use of small intestinal biopsy in clinical practice. Since the second half of the 1970 s, only decreasing ${ }^{1-6}$ or unchanged ${ }^{7}$ inci- $^{-}$ dences have been reported, and the figures have varied among populations. Some differences are the result of varying diagnostic criteria, and others of the lack of standardised epidemiological approaches with subsequent difficulties in comparison. Some studies were based on figures without relation to a population. ${ }^{422}$

One important problem of longitudinal epidemiological studies is that of the duration of observation periods of the different birth cohorts (fig 4). To avoid a systematic error with overestimation of the incidence in the older cohorts, it is necessary to maintain the same observation time. A choice must be made between a shorter observation time that will exclude the cases that were diagnosed later, and a longer observation time resulting in a long delay before changes can be identified.

Another problem arises when the total population is divided by the number of cases. The cases must be derived from the birth cohorts which constitute the population at risk. In this study children from the surrounding areas treated in the department, and children who had moved to Göteborg before or after the diagnosis was made, were excluded. Children with coeliac disease who were born in Göteborg but in whom the diagnosis was made after they had moved away from the city were impossible to trace and therefore could not be included in the study. Consequently our cumulative incidence represents a minimum. The number of liveborn children in Göteborg varied between 4845 and 6694/year during the study period.

The migration of the population is yet 
another problem in epidemiological studies. The inward migration of cases and population was well controlled in this study. The occurrence of coeliac disease in the population is not likely to differ between the part of the population that stays and the one that migrates out of the city. As we divided the number of cases into the number of liveborn infants, however, and not into the actual number of the cohort who lived in Göteborg, there will be a systematic error that will increase with migration out of the city related to a longer observation time. The number of children with coeliac disease within the birth cohort but in whom the disease was diagnosed after they had moved away from the city will also add to the systematic error with the observation time. There are two ways to adjust for these processes: one is to use a 'life-table' approach, in which the lost part of the cohort is subtracted and the cases are divided into the 'true' denominator. The other approach is to include only the cases in which coeliac disease was diagnosed during a short observation time, for example before 2 years of age, as was done in this study (fig 4). With the last method the problems will be considerably reduced.

Our study is the first to our knowledge to report an increasing incidence in coeliac disease since the beginning of the 1970s. The incidence is one of the highest ever reported, and even higher than those reported from Galway, Ireland $1960-70^{23}$ and from Austria 1969-72, ${ }^{24}$ making coeliac disease one of the most common of the chronic diseases in Swedish children today.

In the last cohorts a lower proportion of cases have fulfilled the ESPGAN criteria so far. This could not explain the observed increase, however, because the number with transient gluten intolerance is low and has been decreasing in our area, as in other parts of Sweden. ${ }^{18}$ In addition, all doubtful cases were excluded from the study.

The increase could consequently not be explained by systematic errors or shortcomings in the methods used. Could it be the result of improved detection? Throughout the study, the same diagnostic criteria were used, and the biopsy specimens were examined by the same two pathologists. The ability to detect and interpret deviations in growth velocity, however, is thought to have improved among physicians and nurses at child health centres. Screening tests for antigliadin antibodies have been in clinical use in the area since the beginning of the 1980s. There is also an increasing awareness of the existence of coeliac disease both among medical staff and the general public. Consequently there has been an increase in the number of small intestinal biopsies done in the department during the study period, and the weight for age at diagnosis has slightly increased (fig 3). All these factors support improved detection as an explanation for the increased incidence. On the other hand, the cases with high weight SD scores could only explain part of the increase (fig 3) and the delay between the onset of symptoms and diagnosis did not change significantly. We also doubt that a different rate of detection could be the sole reason for the different incidence trends in different countries. This indicates that detection bias could only partly explain the observed increase.

We have found a threefold increase in the incidence of coeliac disease over the last 20 years. Our data indicate that only a small part of this increase may be explained by increased diagnostic activities or improved clinical detection or screening. Other factors that may influence the incidence of coeliac disease, such as feeding patterns and gluten consumption, are currently being investigated.

The study was supported by grants from the Göteborg Medical Society, Gothenburg University, the First of May Flower Annua Campaign for Children's Health, and the Wilhelm and Martina Lundgren Foundation.

1 Littlewood JM, Crollick AJ, Richards IDG. Childhood coeliac disease is disappearing. Lancet 1980;ii:1359.

2 Challacombe DN, Baylis JM. Childhood coeliac disease is disappearing. Lancet 1980;ii:1360.

3 Dossetor JFB, Gibson AAM, McNeish AS. Childhood coeliac disease is disappearing. Lancet 1981; i:322-3.

4 Langman MJS, McConnell TH, Spiegelhalter DJ, McConnell RB. Changing patterns of coeliac disease frequency: an analysis of coeliac society membership records. Gut 1985;26:175-8.

5 Logan RFA, Rifkind EA, Busuttil A, Gilmour HM, Ferguson A. Prevalence and 'incidence' of celiac disease in Edinburgh and the Lothian region of Scotland Gastroenterology 1986;90:334-42.

6 Stevens FM, Egan-Mitchell B, Cryan E, McCarthy CF McNicholl B. Decreasing incidence of coeliac disease. Arch Dis Child 1987;62:465-8.

7 Greco L, Tozzi AE, Mayer M, Grimaldi M, Silano G Auricchio S. Unchanging clinical picture of coeliac disease presentation in Campania, Italy. Eur $\mathcal{F}$ Pediatr 1989;148: 610-3.

8 Mäki $\dot{M}$, Kallonen K, Lähdeaho M-L, Visakorpi JK Changing pattern of childhood coeliac disease in Finland. Acta Paediatr Scand 1988;77:408-12.

9 Official Report. Public health in Sweden 1977. Stockholm: National Board of Health and Welfare, 1979.

10 Meeuwisse GW. Diagnostic criteria in coeliac disease. Acto Paediatr Scand 1970;59:461-3.

11 McNeish AS, Harms HK, Rey J, Shmerling DH, Visakorpi JK, Walker-Smith JA. The diagnosis of coeliac disease: a commentary on the current practices of the members of the European Society for Paediatric Gastroenterology and Nutrition (ESPGAN). Arch Dis Child 1979;54:783-6.

12 Fällström SP, Kristiansson B, Ryd W. Histological studies of small intestinal biopsies from infants with low rate of small intestinal biopsies from infants with low rate of
weight gain. Acta Pathologica et Microbiologica Scandiweight gain. Acta Pathologica et

13 Kristiansson B, Karlberg J, Fällström SP. Infants with low rate of weight gain. I. A study of organic factors and growth patterns. Acta Paediatr Scand 1981;70:655-62.

14 Berg NO, Lindberg T. Incidence of coeliac disease and transient gluten intolerance in children in a Swedish urban community. Acta Paediatr Scand 1979;68:397-400.

15 Stenhammar L, Johansson C-G. The incidence of coelia disease in children in south-east Sweden. Acta Paediat Scand 1981;70:379-81.

16 Stenhammar L, Ansved P, Jansson G, Jansson U. The incidence of childhood celiac disease in Sweden. $\mathcal{F}$ Pediat Gastroenterol Nutr 1987;6:707-9.

17 Lindberg $T$. Coelic disease and infant feeding practices. Lancet 1981;i:449.

18 Stenhammar L, Ansved P, Jansson G, Jansson U. Incidences of childhood coeliac disease and transient gluten intolerance move discrepantly in UK and Sweden. Arch Dis Child 1987; 62:1089.

19 Hed J, Lieden G, Ottosson E, et al. IgA anti-gliadin antibodies and jejunal mucosal lesions in healthy blood donors. Lancet 1986;ii:215.

20 Kokkonen J, Similä S, Vuolukka $P$. The incidence of coeliac disease and pyloric stenosis in children in northern Finland. Ann Clin Res 1982;14:123-8.

21 Van Stirum J, Baerlocher K, Fanconi A, Gugler E, Shmerling DH. The incidence of coeliac disease in childre in Switzerland. Helv Paediatr Acta 1982;37:421-30.

22 Kelly DA, Phillips AD, Elliott EJ, Dias JA, Walker-Smith JA. Rise and fall of coeliac disease 1960-85. Arch Dis Child 1989;64:1157-60.

23 Mylotte M, Egan-Mitchell B, McCarthy CF, McNicholl B Incidence of coeliac disease in the west of Ireland. $B M \mathcal{J}$ 1973;i:703-5.

24 Rossipal E. Häufigkeit der Cöliakie im Einzugsgebiet der Kinderklinik Graz. Zeitschrift fur Kinderheilkunde 1975;119 143-9. 